\title{
Erratum to: Mining NGS transcriptomes for miRNAs and dissecting their role in regulating growth, development, and secondary metabolites production in different organs of a medicinal herb, Picrorhiza kurroa
}

Ira Vashisht • Prashant Mishra • Tarun Pal • Sreekrishna Chanumolu • Tiratha Raj Singh • Rajinder Singh Chauhan

Published online: 24 February 2015

(c) Springer-Verlag Berlin Heidelberg 2015

Erratum to: Planta

DOI 10.1007/s00425-015-2255-y

Regrettably, the wrong Fig. 3 was published in the official online publication. The correct Fig. 3 is given in next page.

The online version of the original article can be found under doi:10.1007/s00425-015-2255-y.

I. Vashisht $\cdot$ P. Mishra $\cdot$ T. Pal $\cdot$ S. Chanumolu .

T. R. Singh · R. S. Chauhan $(\bowtie)$

Department of Biotechnology and Bioinformatics, Jaypee

University of Information Technology, Waknaghat,

Solan 173234, Himachal Pradesh, India

e-mail: rajinder.chauhan@juit.ac.in 

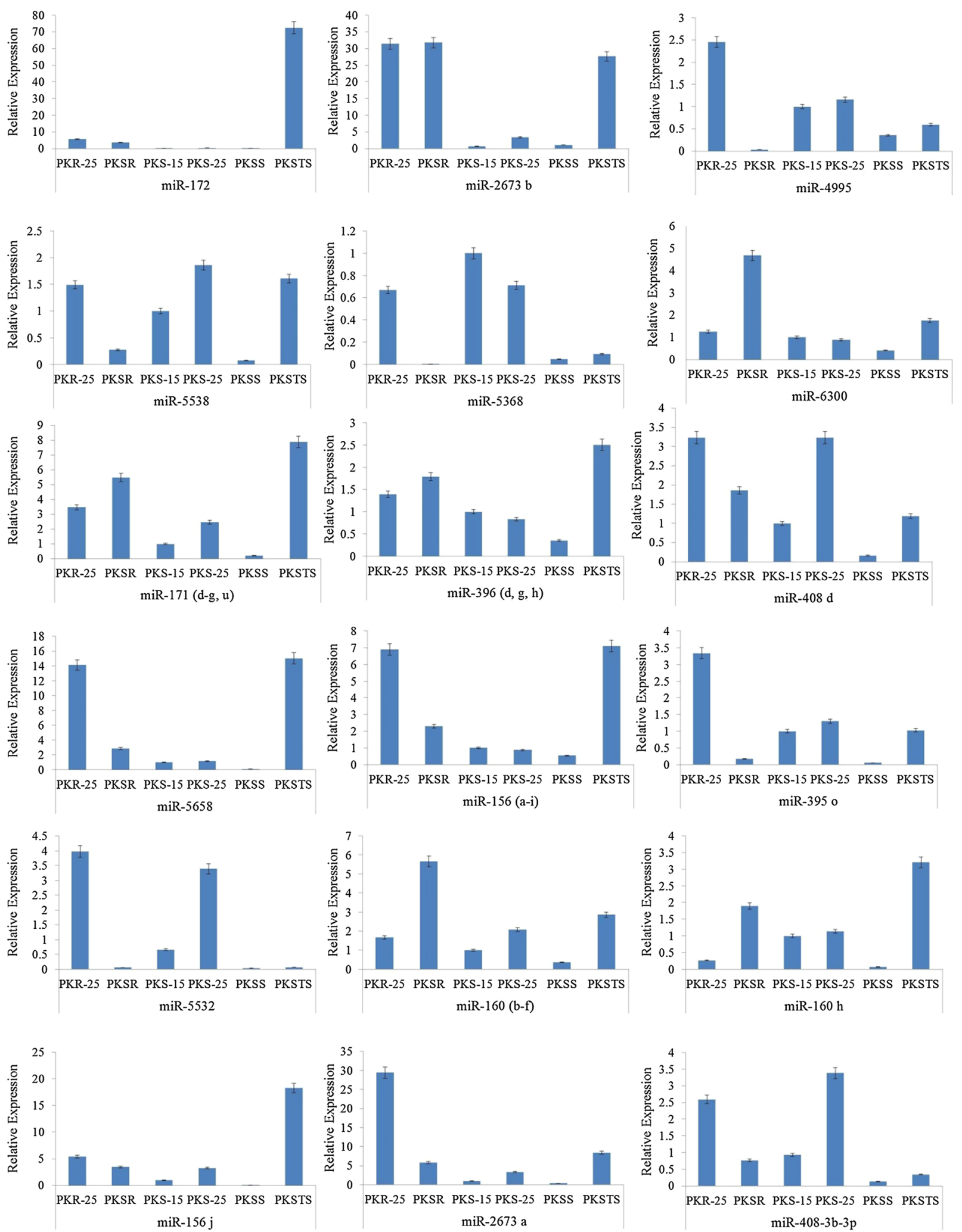

Fig. 3 qRT-PCR profile showing relative expression of miRNAs in six samples of $P$. kurroa. PKR-25-in vitro-cultured roots at $25^{\circ} \mathrm{C}$; PKSR-field-grown roots; PKS-15-in vitro-cultured shoots at $15{ }^{\circ} \mathrm{C}$;
PKS-25-in vitro-cultured shoots at $25^{\circ} \mathrm{C}$; PKSS-field-grown shoots; PKSTS-field-grown stolons. Error bars correspond to percentage error $(5 \%)$ 